NANO: Brief Reports and Reviews

Vol. 7, No. 1 (2012) 1250002 (10 pages)

(C) World Scientific Publishing Company

DOI: $10.1142 /$ S1793292012500026

\title{
OPTIMIZATION OF THE EXPERIMENTAL CONDITIONS IN SYNTHESIS OF Au NPs USING PREYSSLER HETEROPOLY ACID BASED ON THE TAGUCHI ROBUST DESIGN
}

\author{
ALI AYATI* and ALI AHMADPOUR ${ }^{\dagger}$ \\ Department of Chemical Engineering \\ Ferdowsi University of Mashhad \\ 917r948944-1111 Mashhad, Iran \\ *ayati_a_ali@yahoo.com \\ †ahmadpour@um.ac.ir \\ FATEMEH F. BAMOHARRAM \\ Department of Chemistry, Mashhad Branch \\ Islamic Azad University \\ 91735-413 Mashhad, Iran \\ abamoharram@yahoo.com \\ MAJID M. HERAVI \\ Department of Chemistry, School of Sciences \\ Alzahra University, 1993891176 Tehran, Iran \\ mmh1331@yahoo.com
HAMED RASHIDI
Department of Chemical Engineering
Ferdowsi University of Mashhad
917r948944-1111 Mashhad, Iran
hamed_rsh2003@yahoo.com

Received 25 July 2011

Accepted 22 December 2011

Published 28 February 2012

\begin{abstract}
Preparation of gold nanoparticles by chemical reduction method using Preyssler heteropolyacid was investigated. The experimental conditions have been optimized using Taguchi robust design method with L9 orthogonal array. Particle size of the gold nanoparticles was considered as the property in the optimization. Amounts of Preyssler heteropolyacid, $\mathrm{pH}$ and irradiation time were selected as the main parameters. The result of Taguchi analysis has shown that in this process, the preyssler acid amount is the most influencing parameter on the size of gold nanoparticle. Also, the effects of different parameters are in order to: Preyssler acid amount $>\mathrm{pH}>$ irradiation time (negligible). This method showed that decreasing Preyssler amount and increasing $\mathrm{pH}$ of solution lead to formation of smaller nanoparticles. Finally, the prepared
\end{abstract}

†Corresponding author. 
nanoparticles at optimum condition with a size of about 6.42 were characterized by using Dynamic Light Scattering (DLS) method, transmission electron microscopy (TEM), and UV-Vis spectroscopy.

Keywords: Au nanoparticles; Preyssler; photochemical reduction method; Taguchi robust design; optimization.

\section{Introduction}

Metal and metal alloy nanoparticles (NPs) have many important applications in electronics, dental, and chemical industries. ${ }^{1,2}$ They can been prepared by several methods such as thermal, ${ }^{3}$ photochemical, ${ }^{4}$ radiolytic, ${ }^{5}$ electrochemical, ${ }^{6}$ or sonochemical methods ${ }^{7}$ by means of various reagents. Among these metal nanoparticles, Au NPs have been used in the variety of applications such as biomedical monitoring, decorative inks, cosmetics, and lubricants. ${ }^{8}$

One of the important applications of Au NPs is in the catalytic reactions, as they can be very effective catalysts. ${ }^{9}$ Catalysts based on Au NPs are unique in their activity under mild conditions, even at ambient temperature or less. ${ }^{8}$ Therefore, the existing processes can be operated at considerably lower reaction temperatures by using these catalysts, which is hopeful for the development of energy efficient processes. ${ }^{10,11}$ This property also affords a motivating analogue to enzyme catalysis, which can take place at room temperature. ${ }^{12}$

There are many investigations in the production of $\mathrm{Au}$ NPs with a controlled particle size and particle size distribution. ${ }^{13,14}$ A literature review shows that there are limited reports in the green synthesis of $\mathrm{Au}$ NPs using Polyoxometalates (POMs). ${ }^{15-17}$ POMs act as reducing agents, photocatalysts, and stabilizers in the metal nanoparticle synthesis. ${ }^{15,18}$ One of the attractive properties of POMs is that their structures remain unchanged under stepwise, multi electron redox reactions. ${ }^{19}$ It was also shown that POMs can be readily reduced in a variety of ways, for instances, photochemically, electrolytically and with various oxidants, such as $\mathrm{O}_{2}$ or $\mathrm{H}_{2} \mathrm{O}_{2} \cdot{ }^{19,20}$

Troupis et al. have demonstrated that several metal ions including $\mathrm{Ag}^{+}, \mathrm{Pd}^{2+}, \mathrm{Pt}^{3+}$ and $\mathrm{Au}^{3+}$ could form metal nanoparticles in the presence of photochemically activated Keggin polyoxometalates $\left(\left[\mathrm{SiW}_{12} \mathrm{O}_{40}\right]^{5-}\right.$ and $\left.\left[\mathrm{PW}_{12} \mathrm{O}_{40}\right]^{4-}\right) \cdot{ }^{15}$ Mandal and coworkers have reported that room temperature photochemically generated $\left[\mathrm{PW}_{12} \mathrm{O}_{40}\right]^{4-}$ - capped gold NPs enable the reduction of $\mathrm{Ag}^{+}$on the surface of the gold nanoparticles to form $\mathrm{Au}-\mathrm{Ag}$ core-shell bimetallic NPs under further irradiation of UV light. ${ }^{21}$ Recently, Niu and coworkers have investigated formation of Au NPs using photoreduction of transition metal monosubstituted Keggin heteropolyanions $\left[\mathrm{PW}_{11} \mathrm{MO}_{39}\right]^{n-}\left(\mathrm{M}=\mathrm{Cu}^{2+}, \mathrm{Ni}^{2+}, \mathrm{Zn}^{2+}, \mathrm{Fe}^{3+}\right) .{ }^{22}$ Moreover, in our previous works, we have introduced Preyssler acid and molybdophosphoric acid as two reducing agents and efficient stabilizers for the synthesis of $\mathrm{Au} \mathrm{NPs}{ }^{23,24}$

Although, the Keggin-type and mixed-valance POMs and Preyssler have been used in the synthesis of $\mathrm{Au} \mathrm{NPs}$, to the best of our knowledge, there is not any report considering the optimum condition using statistical analysis methods. We have selected Preyssler acid to synthesize Au NPs in a photocatalytic method and to find optimum conditions in this process. Among various POMs, Preyssler acid is unique because of many advantages, including strong Bronsted acidity, high hydrolytic stability $(\mathrm{pH}=0-12)$, high thermal stability, corrosiveness, safety, and greenness. ${ }^{25}$

The analysis of this chemical reduction method to find optimized factors is a time and labor-consuming work due to the complexity of interrelationships between these factors. This analysis is inefficient by using the conventional experimental methods. So, Taguchi robust design method ${ }^{26,27}$ was applied in the present study. There is no report in the synthesis of gold nanoparticles using POMs by chemical reduction route using Taguchi robust design method.

The method was developed by Genichi Taguchi between 1950 and 1960 to improve the execution of total quality control in Japan. ${ }^{28}$ This is a simple and systematic approach to optimize design parameters for better performance, quality, and cost. ${ }^{29-31}$ Taguchi method is a combination of mathematical and statistical techniques used in an experiential study. It uses fewer experiments in order to study all levels of input parameters and filters out some effects due to the statistical variation. Therefore, the method is very economical for characterization of complex processes. Using the 
above technique, we can determine the experimental conditions having the smallest amount of variability as the optimum condition. The variability can be expressed by signal to noise $(\mathrm{S} / \mathrm{N})$ ratio. $^{26}$ The variability of a property is due to "noise factor", which is a factor difficult to control. On the contrary, the factor easy to control is called "control factor". The experimental condition having the maximum $\mathrm{S} / \mathrm{N}$ ratio is considered as the optimal condition, as the variability of characteristics is in inverse proportion to the $\mathrm{S} / \mathrm{N}$ ratio. ${ }^{26}$

In this work $\mathrm{Au}$ NPs were synthesized with a green and efficient reducing agent, Preyssler heteropolyacid. The Taguchi robust design was also applied for optimization of parameters to obtain $\mathrm{Au}$ NPs with smaller size and narrower particle size distribution by using optimal synthesis conditions. Also, the effect of each parameter on the particle size and its distribution were evaluated.

\section{Experimental}

\subsection{Materials}

$\mathrm{HAuCl}_{4} \cdot 3 \mathrm{H}_{2} \mathrm{O}$ and propan-2-ol (analytical grade) and all other chemicals were obtained from Merck
Company and used as received. Preyssler heteropolyacid $\left(\mathrm{H}_{14}\left[\mathrm{NaP}_{5} \mathrm{~W}_{30} \mathrm{O}_{110}\right]\right)$ was prepared according to our earlier works. ${ }^{25}$

Britton-Robinson (B-R) buffers (phosphate, acetate and borate) in the $\mathrm{pH}$ range of $2-5$ were also used.

\subsection{Experimental procedure}

$\mathrm{Au}$ NPs were prepared by photochemical reduction method. First, $10 \mathrm{~mL}$ of $\mathrm{HAuCl}_{4}$ solution $(0.001 \mathrm{M})$ was added to beaker containing $5 \mathrm{~mL}$ of Preyssler heteropolyacid in buffer solution and then propan-2ol was added to the mixture under stirring. The solution was deaerated with $\mathrm{N}_{2}$ for $30 \mathrm{~min}$ and then irradiated by UV light ( $125 \mathrm{~W}$ high pressure mercury vapor lamp) under continuous stirring. After a specific time, the color of the solution changed to pink, indicating the formation of gold NPs. The prepared nanoparticles were separated in a high speed centrifuge at $14000 \mathrm{rpm}$ for $15 \mathrm{~min}$ and washed twice with DI water. Then, the NPs were dispersed in DI water for characterization. A schematic diagram of the experimental procedure is shown in Fig. 1.

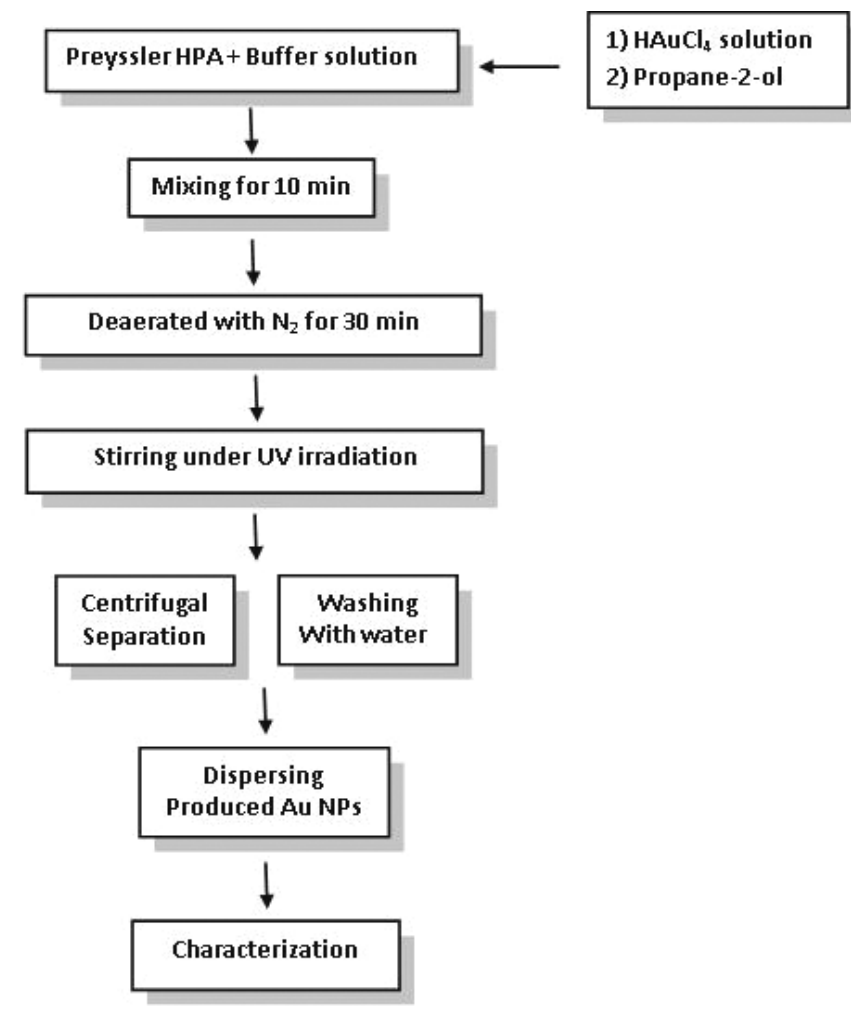

Fig. 1. Experimental procedure for the synthesis of Au NPs. 
Table 1. Parameters and levels used in the experiments using Taguchi robust design method with L9 orthogonal array.

\begin{tabular}{clccc}
\hline & \multicolumn{1}{c}{ Levels } \\
\cline { 3 - 5 } Symbol & Parameter & Low (1) & Medium $(2)$ & High $(3)$ \\
\hline $\mathbf{A}$ & Concentration of Preyssler heteropolyacid (M) & $6.70 \times 10^{-7}$ & $1.33 \times 10^{-6}$ & $4.00 \times 10^{-6}$ \\
$\mathbf{B}$ & $\mathrm{pH}$ & 2 & 3 & 5 \\
$\mathbf{C}$ & Irradiation time (min) & 45 & 90 & 150 \\
\hline
\end{tabular}

\subsection{Characterization of Au NPs}

The prepared Au NPs were characterized mainly based on their DLS, using a laser particle size analyzer (ZetaSizer Nano ZS, Malvern Instruments Ltd.). This instrument allows to measure particle size taking advantage of optoelectronic systems and particle size is measured by the noninvasive backscattering (NIBS) technique.

The synthesized NPs at optimum conditions were characterized by using TEM (PHILIPS CM120 transmission electron microscope instrument) and UV-Vis spectrophotometer (Agilent 8453, Hewlett-Packard, USA).

\subsection{Orthogonal array and experimental parameters}

In this work, the molar concentration of Preyssler heteropolyacid was varied in the range of $6.7 \times$ $10^{-7} \mathrm{~mol}$ to $4.00 \times 10^{-6} \mathrm{~mol}$. $\mathrm{Au}^{3+}$ ions concentration and propan-2-ol amount were fixed at $0.001 \mathrm{M}$ and $2 \mathrm{~mL}$, respectively. In addition, the $\mathrm{pH}$ of solution was between 2 to 5 and irradiation time varied in the range of $45-150 \mathrm{~min}$. Description of parameters and their levels are shown in Table 1.

Taguchi orthogonal array table was used by choosing three parameters that could affect the particle size. ${ }^{32,33}$ For the Taguchi design and subsequent analysis, Minitab software (version 14.1) was used. The proper orthogonal array for the experiments was determined by the software. By selecting $\mathrm{L}_{9}$ orthogonal array, using the three above mentioned parameters and their levels (shown in Table 2), the number of required experiments can be significantly reduced. Three 3-level parameters can be positioned in a $\mathrm{L}_{9}$ orthogonal array table. The numbers 1,2 , and 3 in Table 2 indicate the first, second, and third levels of a factor, respectively.

\section{Results and Discussion}

Preyssler heteropolyacid was chosen to study the synthesis of $\mathrm{Au}$ NPs in a reaction between the reduced Preyssler $\left(\left[\mathrm{NaP}_{5} \mathrm{~W}_{30} \mathrm{O}_{110}\right]^{15-}\right)$ and $\mathrm{Au}^{3+}$ ions. The reduced form of Preyssler ion was achieved by photolysis of a deaerated aqueous solution of propan-2-ol and $\left[\mathrm{NaP}_{5} \mathrm{~W}_{30} \mathrm{O}_{110}\right]^{14-}$, in which propan-2-ol plays the role of sacrificial agent:

$$
\begin{aligned}
& 2\left(\mathrm{NaP}_{5} \mathrm{~W}_{30} \mathrm{O}_{110}\right)^{14-}+\left(\mathrm{CH}_{3}\right)_{2} \mathrm{CHOH} \\
& \quad \rightarrow 2\left(\mathrm{NaP}_{5} \mathrm{~W}_{30} \mathrm{O}_{110}\right)^{15-}+\left(\mathrm{CH}_{3}\right)_{2} \mathrm{C}=\mathrm{O}+2 \mathrm{H}^{+} .
\end{aligned}
$$

Table 2. Experimental measured particle size values and $\mathrm{S} / \mathrm{N}$ ratios for Au NPs.

\begin{tabular}{cccccc}
\hline & & & & \multicolumn{2}{c}{ Average particle size } \\
\cline { 5 - 6 } Experiment No. & $\mathrm{A}$ & $\mathrm{B}$ & $\mathrm{C}$ & Raw data $(\mathrm{nm})$ & S/N Ratio (dB) \\
\hline 1 & 1 & 1 & 1 & 21.13 & -26.50 \\
2 & 1 & 2 & 2 & 12.34 & -21.83 \\
3 & 1 & 3 & 3 & 6.42 & -16.15 \\
4 & 2 & 1 & 2 & 44.73 & -33.01 \\
5 & 2 & 2 & 3 & 23.85 & -25.55 \\
6 & 2 & 3 & 1 & 19.24 & -38.60 \\
7 & 3 & 1 & 3 & 85.12 & -32.61 \\
8 & 3 & 2 & 1 & 42.69 & -29.85 \\
9 & 3 & 3 & 2 & 31.08 & \\
\hline
\end{tabular}


After that, the color of the solution turned gradually from colorless to pink (formation of $\mathrm{Au}^{0}$ ), due to the ability of reduced Preyssler for transferring electrons efficiently to gold ions:

$$
\begin{aligned}
& 3\left(\mathrm{NaP}_{5} \mathrm{~W}_{30} \mathrm{O}_{110}\right)^{15-}+\mathrm{Au}^{3+} \\
& \quad \rightarrow 3\left(\mathrm{NaP}_{5} \mathrm{~W}_{30} \mathrm{O}_{110}\right)^{14-}+\mathrm{Au}^{0} .
\end{aligned}
$$

The above two equations were occurred in a one-pot system at ambient temperature. Preyssler ions can be utilized cyclically as oxidizing or reducing agent according to Eqs. (1) and (2).

There are several vital factors in the formation of $\mathrm{Au}$ nanosized particles using this photochemical reduction procedure. In this method, there are several parameters that affect the size of synthesized $\mathrm{Au}$ NPs, such as Preyssler acid and propan-2-ol amounts, $\mathrm{pH}$ and time of UV irradiation. On the basis of reaction mechanism [Eqs. (1) and (2)], propan-2-ol may have interaction with the first mentioned factor. Then, three other most important parameters (Preyssler acid amount, $\mathrm{pH}$, and irradiation time) that influence the size of $\mathrm{Au}$ NPs, were selected as Taguchi parameters in three levels, which are shown in Table 1.

\subsection{Taguchi experimental design}

A Taguchi robust design method was used to select the parameters having the most principal influence on the particle size of $\mathrm{Au}$ NPs and to find the optimal conditions. Table 2 shows the structure of Taguchi orthogonal robust design and also the results of particle size distribution measurements.

These values show that the Au NPs obtained are in the range of $6.42-85.12 \mathrm{~nm}$. Table 2 represents the mean diameters of samples prepared at conditions and levels mentioned in the table. Also, the size distribution curves of 5 synthesized nanoparticles are shown in Fig. 2. As the DLS curves of Exps. 1, 2, 5, 6 are approximately similar and for more clarification, only Exp. 6 is shown in the figure. As it is seen, most of the synthesized Au NPs are uniform except Exps. 7 and 9. The DLS of Exp. 3 is narrow and synthesized NPs in this experiment are more uniform than others. Diameter of nanoparticles for this experiment are about $4-11 \mathrm{~nm}$. On the other hand, the prepared $\mathrm{Au}$ NPs from Exps. 7 and 9 are not uniform and size of nanoparticles are in the range of $50-190 \mathrm{~nm}$ and $21-68 \mathrm{~nm}$, respectively.

In the Taguchi method, the terms "signal" and "noise" represent the desirable and undesirable values for the output characteristic, respectively. Taguchi method uses the $\mathrm{S} / \mathrm{N}$ ratio to measure the quality characteristic deviating from the desired value. The $\mathrm{S} / \mathrm{N}$ ratios are different according to the type of characteristic (nominal, smallest or biggest is the best) and classified into three groups. ${ }^{34,35} \mathrm{In}$ the case that smaller characteristic is the best; and

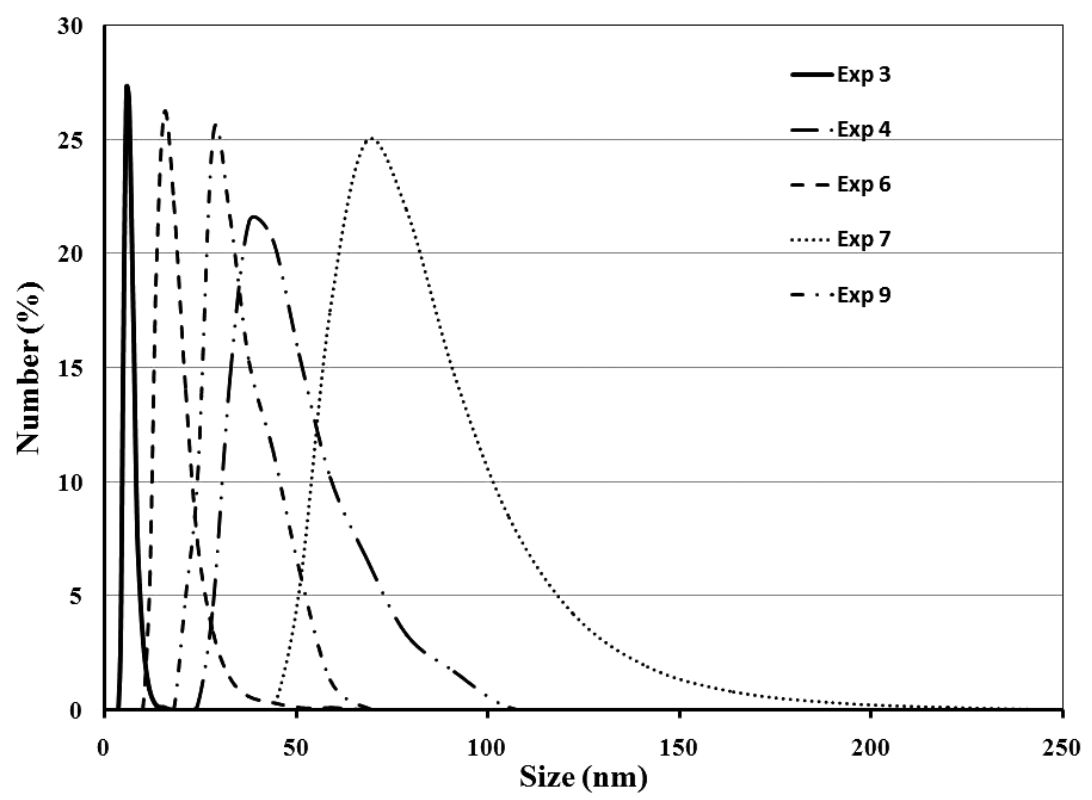

Fig. 2. Size distribution of Au NPs prepared at conditions mentioned in Table 2. 
Table 3. Size to noise ratios for Au particle sizes.

\begin{tabular}{|c|c|c|c|c|c|}
\hline \multirow[b]{2}{*}{ Symbol } & \multirow[b]{2}{*}{ Parameter } & \multicolumn{4}{|c|}{$\mathrm{S} / \mathrm{N}$ ratio $(\mathrm{dB})$} \\
\hline & & Level 1 & Level 2 & Level 3 & Max-Min \\
\hline $\mathrm{A}$ & Preyssler acid amount (mol) & -21.48 & -28.75 & -33.69 & 12.20 \\
\hline $\mathrm{B}$ & $\mathrm{pH}$ & -32.70 & -27.32 & -23.89 & 8.81 \\
\hline $\mathrm{C}$ & Irradiation time (min) & -28.26 & -28.22 & -27.43 & 0.83 \\
\hline
\end{tabular}

the $\mathrm{S} / \mathrm{N}$ ratio is defined as:

$$
\frac{\mathrm{S}}{\mathrm{N}} \text { ratio }[\mathrm{dB}]=-10 \log \left[\frac{y_{1}^{2}+y_{2}^{2}+y_{3}^{2}+\ldots}{n}\right],
$$

where $y_{i}$ is the characteristic property (i.e. particle size in this case) and $n$ is the number of measurements in each experiment. The unit of $\mathrm{S} / \mathrm{N}$ ratio is decibel $(\mathrm{dB})$, which is frequently used in communication engineering. Consistent with its application in engineering and science, the value of $\mathrm{S} / \mathrm{N}$ is proposed to be large; hence, the value of $\left(y_{1}^{2}+y_{2}^{2}+y_{3}^{2}+\ldots / n\right)$ should be small. To find optimal conditions, "the smaller the better" quality characteristic for particle size must be taken. Table 2 shows the $\mathrm{S} / \mathrm{N}$ ratio for particle size using Eq. (3). Since the experimental design is orthogonal, it is then possible to separate out the effect of each parameter at different levels. For example, the mean $\mathrm{S} / \mathrm{N}$ ratio for values of parameter $\mathrm{A}$ at levels 1,2 , and 3 can be calculated by averaging the $\mathrm{S} / \mathrm{N}$ ratios for the experiments $1-3,4-6$, and $7-9$, respectively. In a similar method, the mean $\mathrm{S} / \mathrm{N}$ ratio for each level of the other parameters can be calculated. The mean $\mathrm{S} / \mathrm{N}$ ratio for each level is summarized in Table 3.

As shown in Table 3, the difference between maximum and minimum values of $\mathrm{S} / \mathrm{N}$ values for Preyssler acid amount is the highest. Therefore, it can be found that the amount of Preyssler acid is the most important parameter influencing the gold particle size. Figure 3 clearly shows the S/N response graph for particle size.

As seen in Fig. 3, the effects of parameters are in order of: Preyssler acid amount $>\mathrm{pH}$ of solution $>$ time (the effect of time is insignificant). This figure represents that by decreasing the Preyssler amount, smaller nanoparticles were obtained. This finding verifies our previous results. ${ }^{23}$ This might be due to higher coverage of Preyssler polyanions on the exterior surface of $\mathrm{Au}$ NPs at higher Preyssler concentrations. It is suggested that excess POM adsorption can inhibit further nucleation or promotes

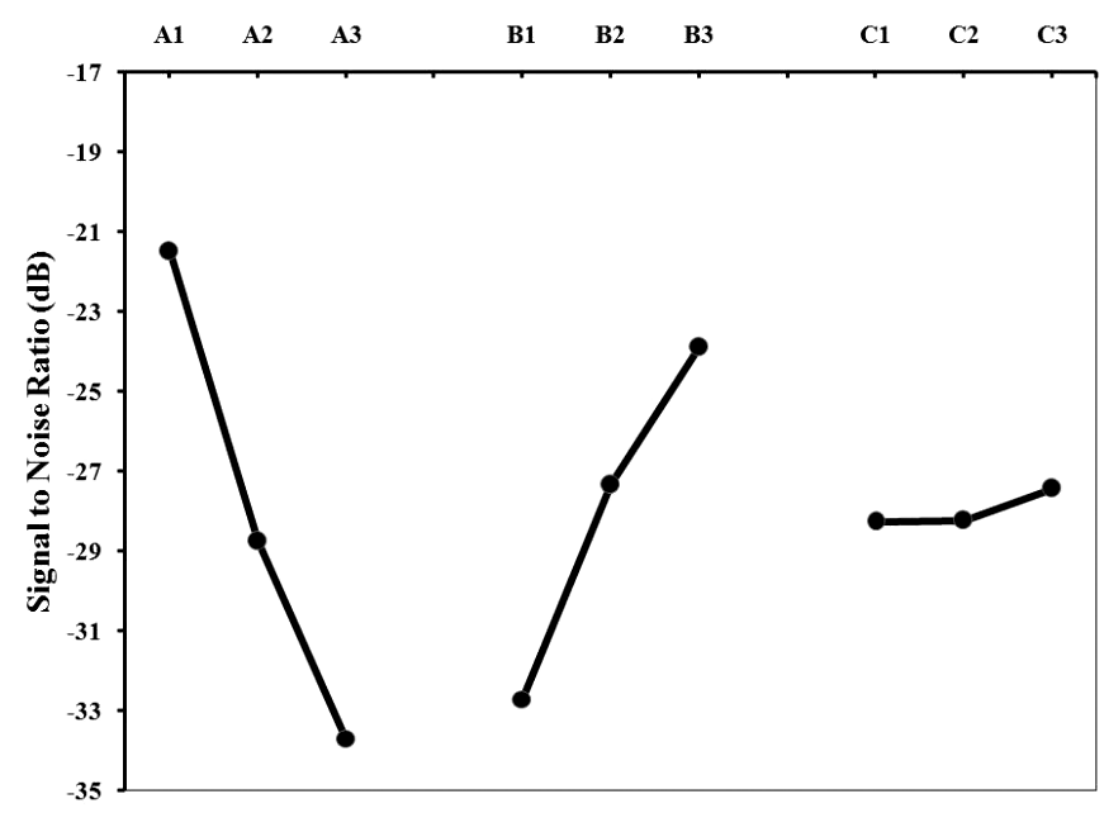

Fig. 3. S/N graphs for particle size of Au NPs. 
coalescence which results in formation of larger particles. Also, this trend for increasing particle size with increasing concentration of a reducing/stabilizing agent can be attributed to kinetic effects. ${ }^{36} \mathrm{In}$ addition, in many practical applications, larger particles could be produced either by slow growth or by aggregation of nanosize precursors. In the latter case, higher concentrations of reactants also favor the formation of such desired dispersions.

Moreover, Fig. 3 represents the dependency of $\mathrm{Au}$ NPs mean diameter to the $\mathrm{pH}$ of the solution. It clearly shows that the NP diameter increases continuously with a decrease in $\mathrm{pH}$. The variation of $\mathrm{pH}$ does not alter the rate of metal ions' recovery during the reaction. ${ }^{37}$ It means that varying the $\mathrm{pH}$ does not change the redox power of Preyssler acid. Therefore, the effect of $\mathrm{pH}$ on the $\mathrm{Au}$ NPs diameter has nothing to do with this. It might be that an electrostatic interaction leads to the dependency of the nanoparticle diameter on $\mathrm{pH}$. Thus, by increasing the $\mathrm{pH}$, electrostatic interaction between the $\mathrm{Au}^{3+}$ ions and Preyssler anions in solution becomes weaker, which leads to decrease in the size of nanoparticles.

Moreover, the strong tetrachloroauric acid $\left(\mathrm{HAuCl}_{4}\right)$, the most accessible source of $\mathrm{Au}^{3+}$, totally dissociates in aqueous solutions generating $\mathrm{AuCl}^{4-}$ complex ions of square planar geometry. At the low pH, the absorption bands at 226 and $312 \mathrm{~nm}$, corresponding to the $p_{\pi} \rightarrow 5 d x^{2}-y^{2}$ and $p_{\sigma} \rightarrow 5 d x^{2}-y^{2}$ ligand-metal transitions, clearly indicate the presence of the square planar $\mathrm{AuCl}^{4-}$ complex ions. ${ }^{38}$

At higher $\mathrm{pHs}(\mathrm{pH} \geq 6)$, the insertion of the $\mathrm{OH}^{-}$ions in the inner coordination sphere proceeds, so chlorinated and hydroxylated complexes of gold can form. ${ }^{39}$ In addition, in the dilute solutions $\left(<10^{-2} \mathrm{M} \mathrm{Au}^{3+}\right)$, the formation of hydroxo complexes is a much slower process. With respect to the above statement, we have worked with $10^{-3} \mathrm{M} \mathrm{Au}^{3+}$ at $\mathrm{pH}$ range of $2-5$, the conditions that chlorinated and hydroxylated complexes of gold could not be formed.

According to Eq. (3), the greater $\mathrm{S} / \mathrm{N}$ ratio means the smaller variance of particle size around the desired value. Therefore, with respect to Table 2 and Fig. 3, the optimum conditions are A1, B3, and C3. In other words, based on these S/N ratios, the optimal conditions for producing $\mathrm{Au}$ NPs with the smallest particle size are A at level 1, $\mathrm{B}$ and $\mathrm{C}$ at level 3.

\subsection{Analysis of variance (ANOVA)}

The main objective of the ANOVA was to explore in which synthesis parameters significantly affect the size of $\mathrm{Au}$ NPs. The ANOVA is presented in Table A.1. According to the results, the Preyssler acid amount has the greatest variance and the $\mathrm{pH}$ is in the second place. The reaction time has no noticeable effect on the particle size. Also, according to Table 3, for irradiation time the values of $\mathrm{S} / \mathrm{N}$ ratios are close to each other and therefore, this factor can be excluded and pooled ANOVA could be applied. It should be mentioned that the process of elimination a factor with insignificant contribution is called pooling. Table A.2 shows the results of pooled ANOVA.

The percentage contribution and F-ratios are shown in the table. The percentage contribution for Preyssler acid amount is seen to be the highest value (i.e. 47.9) and this value for $\mathrm{pH}$ is 30.8 .

\subsection{Prediction of particle size at optimum conditions}

The optimal level of the design parameters has been chosen according to the previous section. The final step is to predict the enhancement of the quality characteristic using optimal level of the design parameters. The predicted $\mathrm{S} / \mathrm{N}$ ratio using optimal level of the design parameters can be calculated $\mathrm{as}^{27}$ :

$$
\left[\frac{\mathrm{S}}{\mathrm{N}}\right]_{\text {predicted }}=\left[\frac{\mathrm{S}}{\mathrm{N}}\right]_{\mathrm{m}}+\sum_{i=1}^{n}\left(\left[\frac{\mathrm{S}}{\mathrm{N}}\right]_{i}-\left[\frac{\mathrm{S}}{\mathrm{N}}\right]_{\mathrm{m}}\right),
$$

where $[\mathrm{S} / \mathrm{N}]_{\mathrm{m}}$ is the total mean of $\mathrm{S} / \mathrm{N}$ ratio, $[\mathrm{S} / \mathrm{N}]_{i}$ is the mean $\mathrm{S} / \mathrm{N}$ ratio at the optimal level, and $n$ is the number of main design parameters that affect the quality characteristic.

In this case, the value of $[\mathrm{S} / \mathrm{N}]_{\mathrm{m}}$ calculated from Table 2 is -27.97 . Also, $[\mathrm{S} / \mathrm{N}]_{i}$ values for $\mathrm{A} 1, \mathrm{~B} 3$, and C3 obtained from Table 3 are $-21.48,-23.89$ and -27.43 , respectively. By using these values, Eq. (4) can be written as: $[\mathrm{S} / \mathrm{N}]_{\text {predicted }}=-27.97+$ $[(-21.48+27.97)+(-23.89+27.97)+(-27.43+$ $27.97)]=-16.86 \mathrm{~dB}$.

Therefore, the predicted $\mathrm{S} / \mathrm{N}$ ratio $(-18.86)$ for nanoparticle size can be obtained and the corresponding estimated particle size can also be calculated by using Eq. (5). Therefore, Eq. (5) is expressed as $-18.86=-10 \log \left(y^{2}\right)$ and the 


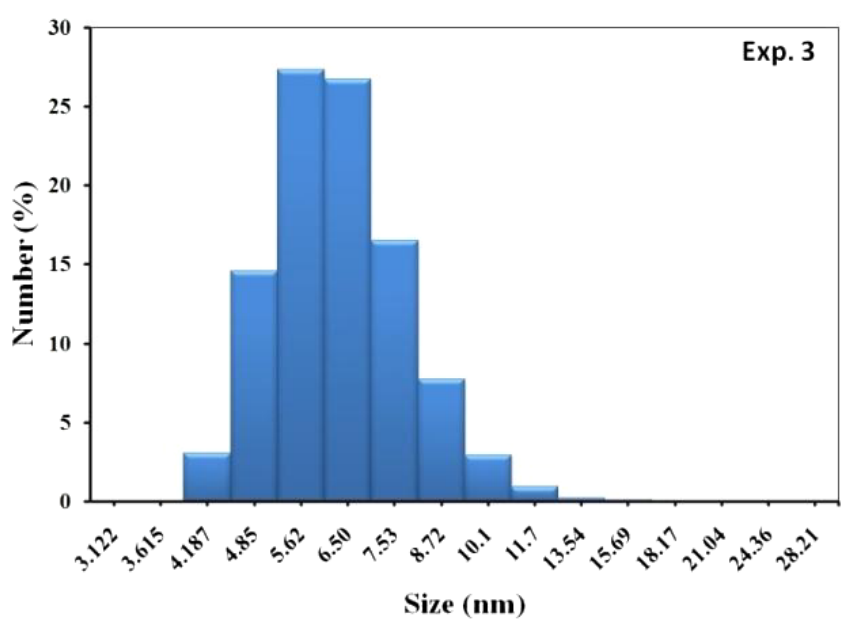

Fig. 4. Size distribution of $\mathrm{Au}$ NPs obtained at optimal experimental conditions (Preyssler acid amount $=6.7 \times 10^{-7}$ $\mathrm{mol}, \mathrm{pH}=5$, propan-2-ol $=2 \mathrm{~mL}$ at $150 \mathrm{~min})$.

Table 4. Results of confirmation experiment at optimal conditions.

\begin{tabular}{|c|c|c|c|}
\hline & Level & $\begin{array}{l}\text { Average particle } \\
\text { size }(\mathrm{nm})\end{array}$ & $\mathrm{S} / \mathrm{N}$ ratio $(\mathrm{dB})$ \\
\hline Prediction & A1B3C3 & 6.96 & -18.86 \\
\hline Experiment & A1B3C3 & 6.42 & -16.15 \\
\hline
\end{tabular}

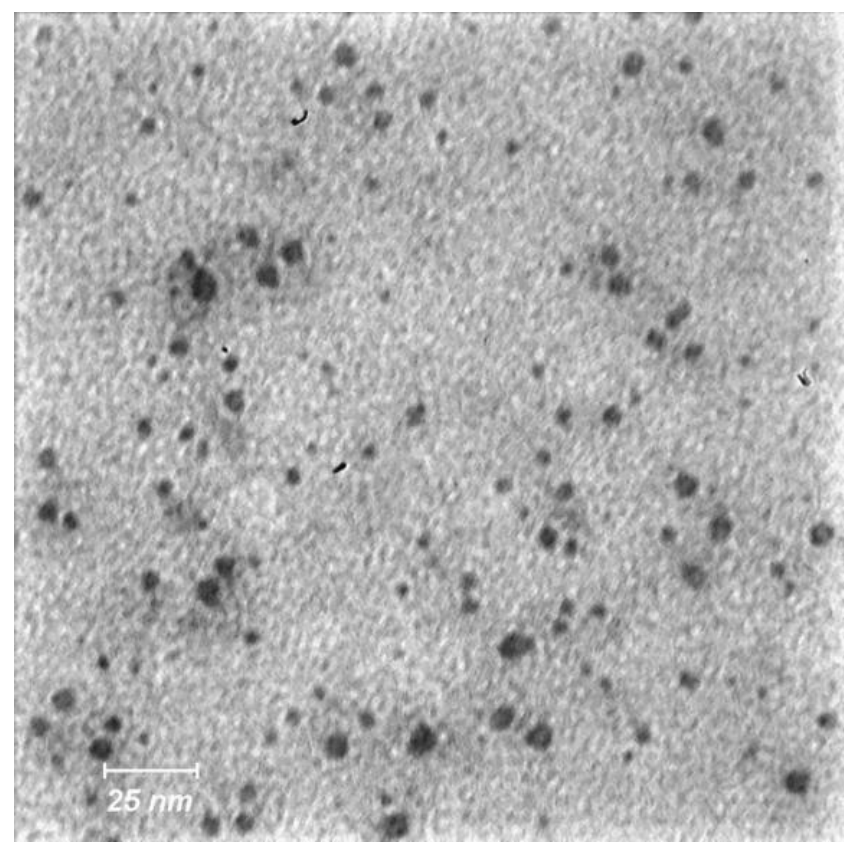

Fig. 5. TEM images of Au NPs obtained at optimal experimental conditions.

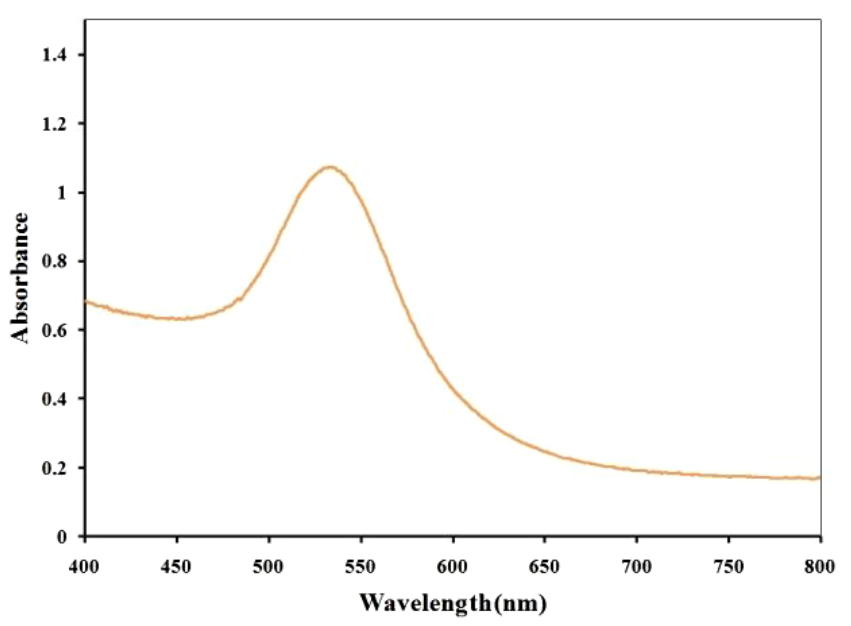

Fig. 6. The UV-Vis absorption spectrum of gold colloidal solution at optimal experimental conditions.

estimated particle size of $6.96 \mathrm{~nm}$ is obtained. The size distribution of confirmation experiment with the optimal condition level is shown in Fig. 4. The narrow distribution of particles indicate the uniformity of Au NPs.

Table 4 shows the comparison between the predicted particle size and $\mathrm{S} / \mathrm{N}$ ratio with those of experiment using optimal conditions, which is one of Taguchi design experiment (exp No. 3).

There is a good agreement between the predicted and the experimental particle sizes. Therefore, by applying the Taguchi method we have reached the smaller size for Au NPs.

Figure 5 shows the TEM images of these Au NPs produced at optimal conditions. As shown in this figure, the $\mathrm{Au} \mathrm{NPs}$ with the size of about $6.42 \mathrm{~nm}$ can be observed. Figure 6 illustrates the UV-Vis absorption spectrum of Au NPs obtained at this optimal condition.

It is known that UV-Vis spectrum of solution including Au NPs shows an surface Plasmon resonance (SPR) band at about $530 \mathrm{~nm} .^{22}$ This observation almost agrees with the theoretical expectations based on the evolution of nanoparticle sizes of $\mathrm{Au}^{40}$ It has been also confirmed by other experimental investigations. ${ }^{41}$

\section{Conclusions}

In this work, nanosized $\mathrm{Au}$ particles were synthesized by chemical reduction method using Preyssler heteropolyacid. The Taguchi robust design method was used for the first time for 
optimization of the experimental parameters to obtain smaller nanoparticle size. As a result, the Preyssler heteropolyacid amount was the most important parameter having major influence on the particle size and DLS of Au NPs. The effects of parameters are found to be in order of: Preyssler acid amount $>\mathrm{pH}>$ time (negligible). By choosing optimal conditions, Au NPs $(6.42 \mathrm{~nm})$ with narrow particle size distribution were prepared and the results were in good agreement with the data analyzed by Taguchi robust design method. Also, the results of UV-Vis absorption confirm the above findings.

\section{References}

1. H. Gleiterand, Nanostruct. Mater. 1, 1 (1992).

2. L. N. Lewisand, Chem. Rev. 93, 2693 (1993).

3. D. V. Goia and E. Matijeviç̧and, New J. Chem. 22, 1203 (1998).

4. M. R. V. Sahyun and N. Serponeand, Langmuir 13, 5082 (1997).

5. K.-S. Chouand and C.-Y. Ren, Mater. Chem. Phys. 64, 241 (2000)

6. M. T. Reetz and W. Helbigand, J. Am. Chem. Soc. 116, 7401 (1994).

7. Y. Nagata, Y. Watananabe, S. I. Fujita, T. Dohmaru and S. Taniguchiand, J. Chem. Soc. Chem. Commun. 16, 1620 (1992).

8. D. T. Thompson, Nano Today 2, 40 (2007).

9. M. Haruta, T. Kobayashi, H. Sano and N. Yamada, Chem. Lett. 16, 405 (1987).

10. D. H. Kim, M. C. Kung, A. Kozlova, S. D. Yuan and H. H. Kung, Catal. Lett. 98, 11 (2004).

11. R. Burchand, Phys. Chem. Chem. Phys. 8, 5483 (2006).

12. B. Hvolbæk, T. V. W. Janssens, B. S. Clausen, H. Falsig, C. H. Christensen and J. K. Norskov, Nano Today 2, 14 (2007).

13. A. Safavi and S. Zeinali, Coll. Surf. A Physicochem. Eng. Asp. 362, 121 (2010).

14. L. N. Ma, D. J. Liu and Z. X. Wang, Chin. J. Anal. Chem. 38, 1 (2010).

15. A. Troupis, A. Hiskia and E. Papaconstantinou, Angew. Chem. Int. Ed. 41, 1911 (2002).

16. F. F. Bamoharram, Synth. Reac. Inorg. Met.-Org. Nano-Met. Chem. 41, 893 (2011).

17. F. F. Bamoharram, A. Ahmadpour, M. M. Heravi, A. Ayati, H. Rashidi and B. Tanhaei, Synth. Reac. Inorg. Met.-Org. Nano-Met. Chem. 42, 1 (2012).

18. S. Mandal, A. Das, R. Srivastava and M. Sastry, Langmuir 21, 2408 (2005).
19. I. A. Weinstock, Chem. Rev. 98, 113 (1998).

20. E. Papaconstantinou, Chem. Soc. Rev. 18, 1 (1989).

21. S. Mandal, P. R. Selvakannan, R. Pasrich and M. Sastry, J. Am. Chem. Soc. 125, 8440 (2003).

22. C. Niu, Y. Wu, Z. Wang, Z. Li and R. Li, Front. Chem. Chin. 4, 44 (2009).

23. A. Ayati, A. Ahmadpour, F. F. Bamoharram, M. M. Heravi and H. Rashidi, Chin. J. Catal. 32, 978 (2011).

24. A. Ayati, A. Ahmadpour, F. F. Bamoharram, M. M. Heravi, H. Rashidi and B. Tanhaei, Int. J. Nanosci. Nanotechnol. (2012), in press.

25. F. F. Bamoharram, M. M. Heravi, M. Roshan, M. Jahangir and A. Gharib, Appl. Catal. A-Gen. 302, $42(2006)$.

26. P. J. Ross, Taguchi Techniques for Quality Engineering (McGraw-Hill, New York, 1988).

27. R. Roy, A Primer on the Taguchi Method (Van Nostrand Reinhold, New York, 1990).

28. G. Taguchi, Y. Yokoyama and Y. Wu, Taguchi Methods/Design of Experiments (American Supplier Institute Press, Tokyo, 1993).

29. D. C. Montgomery, Introduction to Statistical Quality Control, 5th edn. (John Wiley \& Sons Inc., New York, 2001).

30. S. H. Park, Robust Design and Analysis for Quality Engineering (Chapman \& Hall, London, 1996).

31. D. R. Cox and N. Reid, The Theory of the Design of Experiments (Chapman \& Hall/CRC, 2000).

32. G. Taguchi, Experimental Designs (Maruzen Co., Tokyo, 1962).

33. S. K. Park, K. D. Kim and H. T. Kim, Coll. Surf. A 197, 7 (2002).

34. G. Taguchi, Introduction to Quality Engineering (Asian Productivity Organization, Tokyo, 1990).

35. A. Bendell, J. Disney and W. A. Pridmore, Taguchi Methods: Applications in World Industry (IFS Publications, UK, 1989).

36. S. K. Sivaraman, I. Elango, S. Kumar and V. Santhanam, Curr. Sci. 97, 1055 (2009).

37. L. Yang, Y. Shen, A. Xie, J. Liang, S. Li and Q. Zhang, Eur. J. Inorg. Chem. 22, 4658 (2006).

38. R. J. Puddephatt, The Chemistry of Gold (Elsevier, Amsterdam, 1978).

39. D. V. Goia and E. Matijevic, Coll. Surf. A 146, 139 (1999).

40. A. M. Schwartzberg and J. Z. Zhang, J. Am. Chem. Soc. 112, 10323 (2008).

41. G. Zhang, B. Keita, R. N. Biboum, F. Miserque, P. Berthet, A. Dolbecq, P. Mialane, L. Catala and L. Nadjo, J. Mater. Sci. 19, 8639 (2009). 


\section{Appendix A}

Table A.1. Analysis of variance (ANOVA) for all factors.

\begin{tabular}{|c|c|c|c|c|c|c|}
\hline Factor & $\begin{array}{c}\text { Degree of } \\
\text { freedom (DOF) }\end{array}$ & Sum of squares (SS) & Variance $(\mathrm{V})$ & F-ratio $(\mathrm{F})$ & Pure sum $\left(\mathrm{S}^{\prime}\right)$ & Percent $\mathrm{P}(\% \mathrm{P})$ \\
\hline $\begin{array}{l}\text { (A) Preyssler } \\
\text { acid amount }\end{array}$ & 2 & 2389.9 & 1194.9 & 8.637 & 2113.2 & 47.1 \\
\hline (B) $\mathrm{pH}$ & 2 & 1618.9 & 809.4 & 5.85 & 1342.2 & 29.9 \\
\hline (C) Irradiation time & 2 & 201.5 & 100.7 & 0.728 & 0 & 0 \\
\hline Other/error & 2 & 276.7 & 138.3 & & & 23.0 \\
\hline Total & 8 & 4487.0 & & & & 100 \\
\hline
\end{tabular}

Table A.2. Pooled analysis of variance.

\begin{tabular}{|c|c|c|c|c|c|c|}
\hline Factor & $\begin{array}{c}\text { Degree of } \\
\text { freedom (DOF) }\end{array}$ & Sum of squares (SS) & Variance $(\mathrm{V})$ & F-ratio $(\mathrm{F})$ & Pure sum $\left(\mathrm{S}^{\prime}\right)$ & Percent $\mathrm{P}(\% \mathrm{P})$ \\
\hline $\begin{array}{l}\text { (A) Preyssler } \\
\text { acid amount }\end{array}$ & 2 & 2389.9 & 1194.957 & 9.996 & 2150.8 & 47.9 \\
\hline (B) $\mathrm{pH}$ & 2 & 1618.9 & 809.432 & 6.771 & 1379.8 & 30.8 \\
\hline (C) Irradiation time & Pooled & & & & & \\
\hline Other/error & 4 & 478.2 & 119.54 & & & 21.3 \\
\hline Total & 8 & 4487.0 & & & & 100 \\
\hline
\end{tabular}

